\title{
Service line management and medical education - uncomfortable bed fellows?
}

\author{
Alex Bailey, ${ }^{1,2}$ James P. Warner ${ }^{1,2}$ \\ The Psychiatrist (2011), 35, 121-123, doi: 10.1192/pb.bp.110.032359 \\ ${ }^{1}$ Central and North West London NHS \\ Foundation Trust \\ ${ }^{2}$ Imperial College London \\ Correspondence to Alex Bailey \\ (alex.bailey@nhs.net) \\ First received 17 Aug 2010, final \\ revision 8 Nov 2010, accepted \\ 16 Dec 2010 \\ Summary The current method of delivery of psychiatric training and education in \\ the UK is still almost solely based on the 'firm' or consultant-led system. Traditionally, \\ these units have had fairly wide-ranging loci of clinical responsibility, ensuring a broad \\ exposure to mental health conditions for both undergraduate students and psychiatric \\ trainees. However, changes over the past decade, particularly in terms of functional \\ splits within psychiatric services, have led to some limitation of this exposure. Various \\ strategies have been employed by those responsible for educational provision within \\ services, such as assigning trainees and students to in-patient and community 'pairs' \\ of teams. Although this has had some success, the introduction of more fundamental \\ restructuring of mental health services and the advent of service lines will have even \\ greater and more wide-ranging implications on education. This editorial examines \\ some of these implications and looks at potential solutions to ensure that training is \\ not forgotten in the wave of far-reaching and strategically driven reorganisations \\ occurring within the National Health Service and more globally.
}

Declaration of interest None.
The advent of Modernising Medical Careers (MMC) and the Postgraduate Medical Education and Training Board (PMETB) along with the publication of Tomorrow's Doctors ${ }^{1}$ by the General Medical Council in 2003 privileged the acquisition of competencies over the accumulation of explicit knowledge in medical education. This was coupled with the introduction of competency assessments in both undergraduate and postgraduate training, principally in the form of workplace-based assessments (WPBAs), formative tools which were designed to cover cognitive areas such as skills and attitudes as opposed to traditional summative assessments which were felt to be overly reliant on the acquisition of knowledge. Despite their many critics, WPBAs have the potential to ensure that trainees and students are exposed to the full gamut of skills necessary to achieve competence in a given specialty. For psychiatry in particular, this may cover areas such as diagnosis, management and high-order communication skills. Workplace-based assessments theoretically also allow formative development of 'higher-level' competencies such as leadership and management skills, teaching, research and audit, and 'professionalism'. However, despite their introduction, and a broad admission by educational governance bodies that students and trainees should rely less on the acquisition of explicit knowledge, this does not appear to have adequately permeated the zeitgeist of medical training among educators and those they teach. Shop-floor delivery of teaching still privileges knowledgebased domains and pressure on this system is now compounded by anxieties over fulfilling competencies in the other domains.
The introduction of the European Working Time Directive (EWTD) has limited the working week of doctors to 48 hours. This has provoked wide-ranging criticisms on the impact this will have on training and professional development $^{2}$ as well as patient care. ${ }^{3}$ Beyond this, the MMC inquiry, ${ }^{4}$ commissioned by the Department of Health and led by Professor Sir John Tooke, widely criticised the strategies proposed by MMC and recommended the formation of a new body, Medical Education England (MEE), to facilitate the interface between policy development and delivery of medical education. This move was championed by Lord Darzi's Next Stage Review, ${ }^{5}$ which named educational policy a critical part of any structural redesign of the National Health Service (NHS). More recently, an MEE consultation authored by Professor Sir John Temple has stated that although high-quality training is theoretically possible within a 48-hour working week, this is 'precluded when trainees have a major role in out of hours service, are poorly supervised and access to learning is limited'. ${ }^{6}$ It is generally held that the move to full-shift working patterns will push training quality down in this way.

\section{Service line management}

Enter service line management. The premise of service line management is that trusts reconfigure their services into discrete units, for example 'in-patient services' or 'organic disorders'. These autonomous units facilitate closer scrutiny of performance and financial management. ${ }^{7}$ Originally 
designed for the acute sector, many mental health trusts are now rapidly implementing this strategy. Trusts may see service line management as a vehicle for implementation of payment by results. An essential component of payment by results is that patients are assigned to a care pathway (cluster) according to need and diagnosis, with each care pathway linked to a specific tariff. This replaces the old system of commissioners block purchasing from providers, with the theoretical intention of streamlining care and driving up efficiency. ${ }^{8}$ Although there are 21 such clusters proposed in mental health provision, many organisations band together similar clusters to form the basis of service lines. Explicit in their design is that clinicians will be narrowly responsible within a particular service line, for example taking on an in-patient service line while having minimal exposure to community patients.

Whereas clinicians struggle to understand the impact of service lines to patient care and service design, it is a sine qua non that educationalists and front-line teachers will be even more perplexed in terms of the pedagogic implications for both undergraduates and psychiatrists in training.

\section{Postgraduate training}

In psychiatry, it is already difficult to meet the demands of the core training curriculum within the current model of 6-month rotations. The blueprinting of WPBAs to this curriculum by PMETB has put huge pressures on trainees to demonstrate the required competencies to their annual review of competence panels. Anticipated cuts in the MultiProfessional Education and Training levy and other workforce constraints as a result of the economic downturn may potentially result in trainees being forced into increasing positions of service provision at the expense of educational and professional development needs.

There is also increasing pressure to reduce the financial burden placed on services through the provision of out-ofhours cover. Non-residential on-calls and 'innovative' adjustments to rotas mean trainees will have a decreased exposure to emergency mental health problems. Although it may be argued that this could lead to a functional increase in the time trainees spend with their teams during the day, it could also be argued that this represents a surreptitious workforce planning strategy to decrease the number of doctors in training. The 'hospital at night' scheme ${ }^{9}$ has not been widely adopted into mental health emergency provision, although the increasing use of non-medical allied health professionals in delivering services in lieu of doctors, as advocated by New Ways of Working, ${ }^{10}$ is potentially damaging for medical training.

Service line management is likely to lead to increasing partition of services, which may limit trainees' overall experience. Although service line management may increase specialisation, which could enhance the depth of exposure within a relatively narrow ambit, it could curtail the breadth of experience as well as hamper junior doctors' ability to make informed career choices. Additionally, the current political and economic environment could result in some services being outsourced from NHS trusts to private or voluntary sector providers, such as substance misuse services, again curtailing training in recognising important facets of mental health such as dual diagnosis.
However, there is light at the end of the tunnel, but postgraduate educators need to start working immediately on innovative solutions to the inevitable introduction of these reorganisations. Shorter training blocks may provide some solution to this, with core trainees training in nine 4-month blocks as opposed to six half-year placements. The disadvantage to this will be poor integration of trainees into individual teams before they have to move on, and reduced opportunities to experience the longitudinal perspective of the patient's journey. Another option could be to introduce super-specialisation early and hence only ask trainees to achieve competencies specific to their subspecialty. Again, a danger here is that psychiatry requires a whole array of generic competencies which are best garnered by experiential exposure to the whole gamut of mental illness. Furthermore, how can we expect our trainees to decide in what specialty they will excel and therefore provide the most 'added benefit' while retaining maximal job satisfaction? A further solution could be to assign trainees to work simultaneously across service lines, although this may lead to significant complexities in service delivery.

The introduction of service line management and an overwhelming call from both the clinical world and the new political administration for doctors to be more directly involved in clinical leadership may erode time available for patient care and teaching. On the other hand, the imperative for senior clinicians to become more involved in day-to-day management of patients can only be a boon to doctors in training. It is far too early to predict what impact this will have on service delivery, let alone on training.

\section{Undergraduate training}

There is little in the way of literature regarding current levels of psychiatric exposure during medical school. The literature abounds with data on attitudes of students towards psychiatry and their choice of it as a career specialty, but there is relatively little in terms of the teaching of psychiatry. One study ${ }^{11}$ has found that the mean time devoted to psychiatry among UK medical schools was 8 weeks, but the range varied from 4 to 11 weeks. Most of this teaching appears to be from clinical academics and NHS psychiatrists, although interestingly there also appear to be large numbers of general practitioners (GPs) involved in the delivery of some psychiatric curricula. This area of primary care psychiatry has not been well researched, but there is evidence of interesting collaborations between primary care and secondary psychiatric services. Given that the psychiatric morbidity that most graduates will encounter will be in either primary or acute settings, these collaborative approaches could offer interesting responses to the difficulties of service line manamgent in delivering undergraduate education. In our trust, for example, an innovative 'speed dating' tutorial uses a psychiatrist, a GP, an approved mental health professional and a police officer to teach students about community psychiatry and the Mental Health Act.

The Association of University Teachers of Psychiatry has produced a model curriculum but this does not appear to have yet been widely adopted. Therefore there is already a lack of clarity regarding different curricula and the resultant level of competence these achieve. It appears 
that approximately half of medical schools currently teach psychiatry as an integrated course, ${ }^{11}$ but it is difficult to imagine at this stage whether this will effectively be able to marry with the framework of service line management.

It is likely that the old system of being assigned to a 'consultant firm' will be untenable and a more collegiate model of teaching will have to be adopted. What must be borne in mind is the potential for this to poorly expose students to longitudinal views of mental illness as well as provide little in the way of modelling behaviour from aspirational teachers. The provision of teaching will inevitably become more complex, and this may complicate teachers' abilities to deal with students who absent themselves.

Teachers of undergraduate psychiatry need to engage proactively with the consequences of service line management. In psychiatry, we are often battling against a tide of disinterested and poorly informed students and little time dedicated to delivering teaching. An enthusiastic and innovative response by those designing psychiatric curricula could lead to an upturn in these fortunes, particularly if the relevance of psychological dysfunction on general health is privileged within teaching structures.

\section{Conclusions}

The NHS has a track record of retroactive adaptation in response to service changes which take place, with little or no consultation with educators. The advent of service line reporting is but one potential tripwire for educationalists and doctors in training alike. The introduction of the government White Paper Liberating the $N H S^{12}$ has unprecedented potential consequences and represents the biggest shake-up in the organisation's 60-year history. Unfortunately, education has historically been woefully left out of these equations. This will occur again at our peril. The devolution of more financial responsibility to trusts through payment by results will inevitably result in them competing to secure referrals and out-bid each other. Consequently, there is a danger that trusts will forget that training and education should be at the heart of everything we do.

There is a subterranean climate of quiet desperation among those involved in medical education at the moment. Although this may be more akin to generalised anxiety disorder than outright panic, this does not make it any less pernicious. We implore all those involved with education students, trainees, teachers, directors of medical education and training programme directors - to keep lines of communication wide open both within and without their community of practice. It is only by innovative thinking and championing the cause of education that we will ride this latest storm of reinvention.

\section{Acknowledgement}

We would like to thank Dr Nisha Dogra for her help with providing material relevant to the content of this article.

\section{About the authors}

Alex Bailey is a specialty trainee in old age psychiatry and teaching fellow, Central and North West London NHS Foundation Trust, and honorary lecturer in the Centre for Mental Health, Department of Medicine, Imperial College London. James P. Warner is a consultant psychiatrist and director of medical education at Central North West London NHS Foundation Trust and honorary reader in psychiatry at Imperial College London.

\section{References}

1 General Medical Council. Tomorrow's Doctors. GMC, 2003 (http://www. gmc-uk.org/static/documents/content/TomorrowsDoctors_2003.pdf).

2 Tsouroufli $M$, Payne $H$. Consultant medical trainers, modernising medical careers (MMC) and the European time directive (EWTD): tensions and challenges in a changing medical education context. BMC Med Educ 2008; 8: 31

3 Devey L. Will modernised medical careers produce a better surgeon? BMJ 2005; 331: 1346

4 Independent Inquiry into Modernising Medical Careers. Aspiring to Excellence: Final Report of the Independent Inquiry into Modernising Medical Careers. MMC Inquiry, 2008

5 Department of Health. High Quality Care for All: NHS Next Stage Review Final Report. Department of Health, 2008.

6 Medical Education England. Time for Training: A Review of the Impact of the European Working Time Directive on the Quality of Training. MEE, 2010 (http://www.mee.nhs.uk/PDF/14274\%20Bookmark\%20 Web\%20Version.pdf).

7 Monitor. Toolkit 1. Working towards Service-Line Management: A How-To Guide. Monitor, 2009 (http://www.monitor-nhsft.gov.uk/home/ourpublications/browse-category/developing-foundation-trusts/serviceline-management/toolkit-1).

8 Department of Health Mental Health Payment by Results Development. Practical Guide to Preparing for Mental Health Payment by Results. Department of Health, 2009 (http://www.dh.gov.uk/prod_consum_dh/ groups/dh_digitalassets/documents/digitalasset/dh_100815.pdf).

9 Mahon A, Harris C, Tyrer J, Carr S, Lowson K, Carr L, et al. The Implementation and Impact of Hospital at Night Pilot Projects. An Evaluation Report. Department of Health, 2005 (http://www.dh.gov.uk /prod_consum_dh/groups/dh_digitalassets/@dh/@en/documents/ digitalasset/dh_4117969.pdf).

10 Care Services Improvement Partnership, National Institute for Mental Health in England. New Ways of Working for Everyone. A Best Practice Implementation Guide. Department of Health, 2007 (http:// www.dh.gov.uk/prod_consum_dh/groups/dh_digitalassets/@dh/@en/ documents/digitalasset/dh_079106.pdf).

11 Karim K, Edwards R, Dogra N, Anderson I, Davies T, Lindsay J, et al A survey of the teaching and assessment of undergraduate psychiatry in the medical schools of the United Kingdom and Ireland. Med Teacher 2009; 31: 1024-9.

12 Department of Health. Equity and Excellence: Liberating the NHS Department of Health, 2010. 